\title{
Rules Research of Neck Curves for 3D Female Body Mannequin
}

\author{
Junqiang SU $\mathrm{U}^{\mathrm{a}, \mathrm{b}, \mathrm{c}}$, Bingfei GU $\mathrm{U}^{\mathrm{a}, \mathrm{b}}$, Guolian LIU*a,b \\ ${ }^{a}$ National Engineering Laboratory for Modern Silk, Suzhou, China; \\ ${ }^{\mathrm{b}}$ College of Textile and Clothing Engineering, Soochow University, Suzhou, China; \\ ${ }^{\mathrm{C}}$ Changzhou Textile \& Garment Institute, Changzhou, China
}

\begin{abstract}
This paper studied the rules of neck curves in constructing 3D female body mannequin used in pattern generation. The main methods used in our research were to determine characteristic points, to insert points and finally got feature curves. Firstly, the breadth, depth and height of these feature parts were got from the three view drawing based on MATLAB to determine the characteristic points through the calculation rules. Secondly, virtual human body model is reconstructed with techniques. Thirdly, determine the left, right, top, bottom and insertion points of each feature curve. Neck curves were taken as an example to explain the method of insertion determination.
\end{abstract}

Keywords: 3D body scanning, neck curve, point cloud data, rule research.

\section{Introduction}

With the development of garment industry, the development and specific application of garment CAD/CAM technology, clothing design and production has been in an automated and high efficiency time. At the same time, higher requirements have been advanced to the key link ---- body measurement of clothing design and production.

In recent decades, the development of human body measurement technology generally undergoes the direction from contact to non-contact type, 2D to 3D and automatic measurement and computer-based measurement, processing and analysis [1].

With the development of technology, advanced 3D body measurement technology, which has the advantage of accurate and quick, will be gradually applied to the actual garment production, and can produce a large number of scanning data with a higher stability in only a few seconds $[2,3]$. Recently the quantitative descriptions of 3D objects have become increasingly important, whereas the traditional measuring method has slow speed, low precision and degree of automation, so it is difficult to meet the needs of rapid measurement for the same type of objects. It has becoming a hotspot of technology research of 3D scanning that how to generate garment pattern rapidly from the point clouds data.

Lin De-jing [4] and so introduced the technique of extraction of the measurement based on the whole 3D scanned body with the following step. Firstly, divide the body into five parts: the legs, arms and the main body. And then used some given planar surface, which intersected the body, to obtain the measurement. Tian Qing-guo [5] researchers presented a measuring approach for figure size from 3D human point cloud. Using a light-stripe 3D laser scanning system to scan the desired pose of body, human's three-dimensional coordinates are obtained without loss. Using this technique, the 34 key figure lengths and girth sizes can be measured, and the factors affecting measurement precision can be analyzed. Measurement results show that the typical measurement error of this method is lower than 3\% and can meet the requirement of industry. Su Jun-qiang [6] extracted the feature lines of 3D body scanning data using Imageware software, which can get the feature cross section of human body rapidly.

Many scholars have explored and researched the fitting projections of the size of circumference, so the fitting approach has been more mature. Regression analysis is a mathematical correlation to deal with the relationship, and is often used in the simulation algorithm of data of 3D body [7]. Qian Qian [8] and other researchers used ellip tic curve and two stage least-squares regression method to calculate the main girths based on the measured data. The results showed that thigh girth and calf girth were described effectively by using ellip tic curve. And two stage least-squares regression method was feasible to describe the four girths. Ge Yan [9] and so used SPSS to carry out mean analysis, correlation analysis and regression analysis of the measured data. Circumference, breadth and thickness dimensions were chosen for regression analysis to establish regression equations. The validity of the equations was tested. 
Based on 3D point-cloud data, this study probes the determination of neck curves. First, the width and thickness of neck were extracted by Matlab from the three view drawing of human body. Second, the key feature point on front/back neck was studied by special rules with the help of insertion points. Third, regression was established by using SPSS to illustrate the relationship among these feature points and insertion points. This study completed part of the work for the conversion from 3D garment pattern to $2 \mathrm{D}$, while provides a new idea for the determination of other baselines in the garment pattern.

\section{Experimental methods}

\subsection{Objects and time of measurement}

In this study, 201 female students at school, aged 18 to 26 years old, height $145 \sim 178 \mathrm{~cm}$, weight 40 $71 \mathrm{~kg}$ of Soochow University were measured between August 2009 to March 2010. The feature points and lines were shown in figure 1, which were extracted by using Matlab from the data of 3D human body scanning.

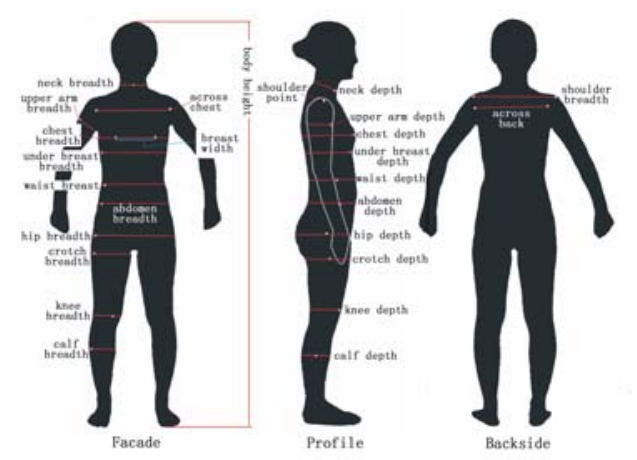

Fig.1. Feature points and lines

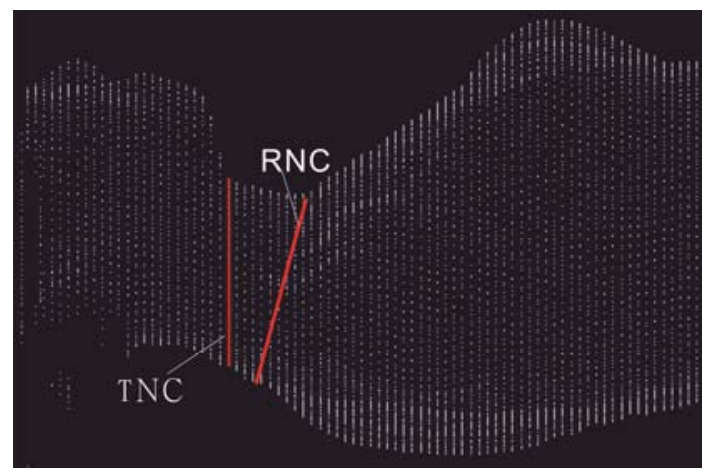

Fig. 2. TNC and RNC

\subsection{Projects of study}

In this study, neck curves were divided into the top neck curves (TNC) and the root neck curves (RNC) and studied separately, as shown in figure 2. In this article, we took the TNC as an example to illustrate our method of research for the rules of neck curves.

\subsection{Study of the top neck curves}

The profile of TNC was obtained by the cross section through the thinnest part of the neck. The method described as follows.

A. Determination of the width and thickness of TNC. We determined the left and right points $A$ and $B$ as the width of neck curve by Matlab in the front view of neck cross-section diagram. And then we linked the two points and made perpendicular line of the line in the left view. The top and bottom points $C$ and $D$ were gotten, which were the most exterior points of the certain area, and the $O$ was the cross point of $A B$ and $C D$, as shown in Figure 3. We defined the width of TNC as JK, which delegates the length of $A B$ and the thickness of TNC as JH (length of $C D$ ), the thickness of the front neck as QJH (the length of $\mathrm{CO}$ ), the thickness of the back neck as HJH (length of OD).

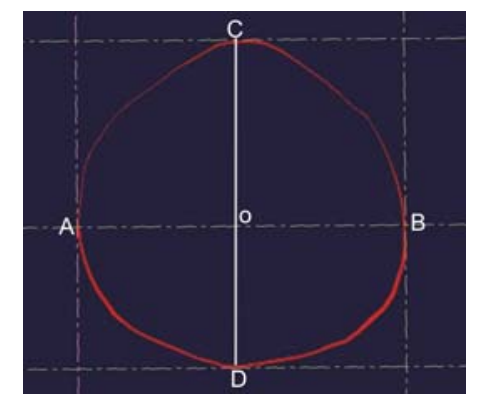

Fig.3. Width and thickness of TNC

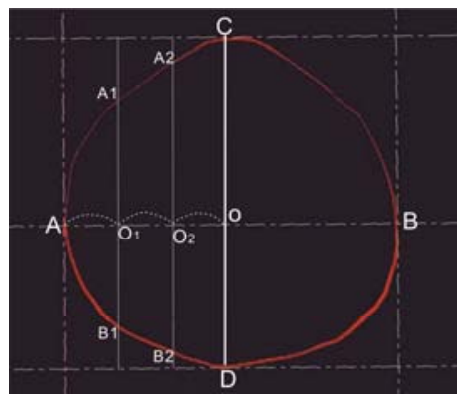

Fig.4. Section of TNC

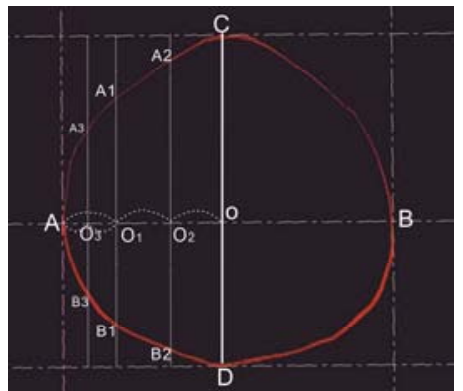

Fig.5. Insertion of TNC

B. Determination of the section on TNC. We measured the distance between the left point and the middle point of neck width line and then trisected. Making the perpendicular line across each triplicate point which jointed the waist curve on $A_{1}, A_{2}, B_{1}$ and $B_{2}$, the result is shown in Figure 4. 
C. Determination of the Insertion points. For the reason that the left and right slope of neck curve was too big that insect three points cannot obtain the best result of simulation by using 3D-B curve. So another insect-point is added between the left point and the first triplicate point. Then the perpendicular line was made to link the neck curve on A3 and B3 which is shown in Figure 5.

D. Measurement. The perpendicular distance between $A_{1}, A_{2}, A_{3}, B_{1}, B_{2}, B_{3}$ and neck width line was measured. There were three groups of data: the thickness of the whole neck (CD), the thickness of front neck ( $C O, A_{1} O_{1}, A_{2} O_{2}, A_{3} O_{3}$ ), the thickness of back neck ( $D O, B_{1} O_{1}, B_{2} O_{2}, B_{3} O_{3}$ ).

\subsection{Rules of TNC}

\subsubsection{Correlation Analysis}

The correlation analysis among the groups above was studied before the regression. We analyzed their correlation with SPSS and the results shown in table 1-3 as follows. In Tables, QJH means "thickness of front neck" (CO), HJH means "thickness of back neck" (DO), JH means "thickness of neck" (CD), JK means "width of neck" (AB).

Table 1 Correlation Analysis on Thickness

\begin{tabular}{|c|c|c|}
\hline & & QJH \\
\hline \multirow{3}{*}{$\mathrm{JH}$} & Pearson Correlation & $0.786^{\star \star}$ \\
\cline { 2 - 3 } & Sig.(2-tailed) & 0.000 \\
\cline { 2 - 3 } & $\mathrm{N}$ & 425 \\
\hline
\end{tabular}

Table 2 Correlation Analysis on Front Insert Point

\begin{tabular}{|c|c|c|c|}
\hline & & $\mathrm{A}_{1} \mathrm{O}_{1}$ & $\mathrm{~A}_{2} \mathrm{O}_{2}$ \\
\hline \multirow{3}{*}{ QJH } & Pearson Correlation & $0.869^{\star \star}$ & $0.760^{\star \star}$ \\
\cline { 2 - 4 } & Sig.(2-tailed) & 0.000 & 0.000 \\
\cline { 2 - 4 } & $\mathrm{N}$ & 425 & 425 \\
\hline
\end{tabular}

Table 3 Correlation Analysis on Back Insert Point

\begin{tabular}{|c|c|c|c|}
\hline & & $\mathrm{B}_{1} \mathrm{O}_{1}$ & $\mathrm{~B}_{2} \mathrm{O}_{2}$ \\
\hline \multirow{3}{*}{$\mathrm{HJH}$} & Pearson Correlation & $0.802^{\star \star}$ & $0.788^{\star \star}$ \\
\cline { 2 - 4 } & Sig.(2-tailed) & 0.000 & 0.000 \\
\cline { 2 - 4 } & $\mathrm{N}$ & 425 & 425 \\
\hline
\end{tabular}

It shows that 1) the Pearson coefficient of correlation between QJH and $\mathrm{JH}$ is 0.786 , the level of significance of two-tailed test was $0.000<0.01$, which means they are significant correlation. 2) The Pearson coefficient of correlation between $\mathrm{A} 1 \mathrm{O} 1$ and $\mathrm{QJH}$ is 0.869 , the level of significance of two-tailed test was $0.000<0.01$, which means they are significant correlation. 3) The Pearson coefficient of correlation between A2O2 and QJH is 0.760, the level of significance of two-tailed test was $0.000<0.01$, which means they are significant correlation. 4) The Pearson coefficient of correlation between $\mathrm{B} 1 \mathrm{O} 1$ and $\mathrm{HJH}$ is 0.802 , the level of significance of two-tailed test was $0.000<$ 0.01 , which means they are significant correlation. 5) The Pearson coefficient of correlation between $\mathrm{B} 2 \mathrm{O} 2$ and $\mathrm{HJH}$ is 0.788 , the level of significance of two-tailed test was $0.000<0.01$, which means they are significant correlation. It shows that the three groups of data are significant correlation on the level 0.01 . It is feasible to study them with regression.

\subsubsection{Regression Analysis}

We took the Q $\mathrm{JH}$ as the dependent variable as well as $\mathrm{JH}$ as the independent variable. The scatter diagram shows that they are linear. Therefore, we suppose the regression model as: $Y=a+b X$. The result of regression is: $\mathrm{Y}=1.236+0.715 \mathrm{X},(\mathrm{Y}-\mathrm{QJH}, \mathrm{X}-\mathrm{JH})$, as shown in Table 4. 
Table 4 The regression result of $Q J H$

\begin{tabular}{|c|c|c|c|c|c|c|}
\hline & \multirow{2}{*}{ Model } & \multicolumn{2}{|c|}{ Unstandardized Coefficients } & \multirow{2}{*}{$\begin{array}{c}\text { Standardized Coefficients } \\
\text { Beta } \\
\end{array}$} & \multirow{2}{*}{$\mathrm{t}$} & \multirow{2}{*}{ Sig. } \\
\hline & & $\mathrm{B}$ & Std. Error & & & \\
\hline \multirow{2}{*}{1} & (Constant) & 1.236 & 1.276 & & 0.968 & 0.338 \\
\hline & $\mathrm{JH}$ & 0.715 & 0.092 & 0.740 & 7.772 & 0.000 \\
\hline
\end{tabular}

We took A1O1, A2O2 as the dependent variable, the QJH as the independent variable. The scatter diagram shows that they are linear. And the regression is: $Y=0.799 X-0.065,(Y-O A 1, X-Q J H)$ and $\mathrm{Y}=0.928 \mathrm{X}-2.281,(\mathrm{Y}-\mathrm{OA} 2, \mathrm{X}-\mathrm{QJH})$, as shown in Table 5 6.

Table 5 The regression result of $A_{1} O_{1}$

\begin{tabular}{|c|c|c|c|c|c|c|}
\hline \multirow{2}{*}{\multicolumn{2}{|c|}{ Model }} & \multicolumn{2}{|c|}{ Unstandardized Coefficients } & \multirow{2}{*}{$\frac{\text { Standardized Coefficients }}{\text { Beta }}$} & \multirow{2}{*}{$\mathrm{t}$} & \multirow{2}{*}{ Sig. } \\
\hline & & $\mathrm{B}$ & Std. Error & & & \\
\hline \multirow{2}{*}{1} & (Constant) & -0.065 & 0.403 & & -0.162 & 0.372 \\
\hline & QJH & 0.799 & 0.065 & 0.869 & 12.320 & 0.000 \\
\hline
\end{tabular}

Table 6 The regression result of $\mathrm{A}_{2} \mathrm{O}_{2}$

\begin{tabular}{|c|c|c|c|c|c|c|}
\hline \multirow{2}{*}{\multicolumn{2}{|c|}{ Model }} & \multicolumn{2}{|c|}{ Unstandardized Coefficients } & Standardized Coefficients & \multirow{2}{*}{$\mathrm{t}$} & \multirow{2}{*}{ Sig. } \\
\hline & & $\mathrm{B}$ & Std. Error & Beta & & \\
\hline \multirow{2}{*}{1} & (Constant) & -2.281 & 0.517 & & -4.415 & 0.007 \\
\hline & QJH & 0.928 & 0.085 & 0.980 & 10.877 & 0.000 \\
\hline
\end{tabular}

a. Dependent Variable: $\mathrm{A}_{2} \mathrm{O}_{2}$.

We took $\mathrm{B}_{1} \mathrm{O}_{1}, \mathrm{~B}_{2} \mathrm{O}_{2}$ as the dependent variable, the $\mathrm{HJH}$ as the independent variable. The scatter diagram shows that they are linear. The result of regression analysis was $\mathrm{Y}=0.411+0.743 \mathrm{X},\left(\mathrm{Y}-\mathrm{OB}_{1}\right.$, $\mathrm{X}-\mathrm{HJH})$ and $\mathrm{Y}=0.479+0.709 \mathrm{X},\left(\mathrm{Y}-\mathrm{OB}_{2}, \mathrm{X}-\mathrm{HJH}\right)$, as shown in Table 7 8.

Table 7 The regression result of $\mathrm{B}_{1} \mathrm{O}_{1}$

\begin{tabular}{|c|c|c|c|c|c|c|}
\hline \multirow{2}{*}{\multicolumn{2}{|c|}{ Model }} & \multicolumn{2}{|c|}{ Unstandardized Coefficients } & \multirow{2}{*}{$\begin{array}{c}\text { Standardized Coefficients } \\
\text { Beta } \\
\end{array}$} & \multirow{2}{*}{$\mathrm{t}$} & \multirow{2}{*}{ Sig. } \\
\hline & & $\mathrm{B}$ & Std. Error & & & \\
\hline \multirow{2}{*}{1} & (Constant) & 0.411 & 0.364 & & 1.129 & 0.264 \\
\hline & $\mathrm{HJH}$ & 0.743 & 0.079 & 0.802 & 9.398 & 0.000 \\
\hline
\end{tabular}

Table 8 The regression result of $\mathrm{B}_{2} \mathrm{O}_{2}$

\begin{tabular}{|l|l|c|c|c|c|c|}
\hline \multirow{2}{*}{ Model } & \multicolumn{2}{c|}{ Unstandardized Coefficients } & Standardized Coefficients & \multirow{2}{*}{$\mathrm{t}$} & \multirow{2}{*}{ Sig. } \\
\cline { 2 - 5 } & $\mathrm{B}$ & Std. Error & Beta & \\
\hline \multirow{2}{*}{1} & (Constant) & 0.479 & 0.794 & & 0.603 & 0.273 \\
\cline { 2 - 6 } & $\mathrm{HJH}$ & 0.709 & 0.164 & 0.888 & 9.311 & 0.000 \\
\hline \multicolumn{2}{|l|}{ a. Dependent Variable: $\mathrm{B}_{2} \mathrm{O}_{2}$} \\
\hline
\end{tabular}




\section{Conclusion}

This paper studied the rules of neck curves in constructing 3D female body mannequin used in pattern generation. The main methods used in our research were to determine characteristic points, to insert points and finally got feature curves.

The results showed that there were significant correlations between QJH and $\mathrm{JH}, \mathrm{An}(\mathrm{n}=1,2,3)$ and QJH and $\mathrm{Bn}(\mathrm{n}=1,2,3)$ and $\mathrm{HJH}$ on the 0.01 level. And then we did the linear regression analysis for every part and the regressions listed as follows:

$$
\begin{aligned}
& Y=1.236+0.715 X,(Y-Q J H, X-J H) . \\
& Y=0.799 X-0.065,\left(Y-\mathrm{OA}_{1}, X-Q J H\right) . \\
& Y=0.928 X-2.281,\left(Y-\mathrm{OA}_{2}, X-Q J H\right) . \\
& Y=0.411+0.743 X,\left(Y-\mathrm{OB}_{1}, X-\mathrm{HJH}\right) . \\
& Y=0.479+0.709 X,\left(Y-\mathrm{OB}_{2}, X-\mathrm{HJH}\right) .
\end{aligned}
$$

This research finished the rules of neck curves in 3D female body mannequin by studying the three-view drawing of point clouds data. It will contribute to further research of virtual fashion exhibition and garment pattern generation automatically, and can be useful to the development of clothing e-commerce.

\section{Acknowledgement}

This paper is funded by the First Phase of Distinctive Discipline Development Program of Universities in Jiangsu Province for Textile Science and Engineering of Soochow University and by the graduate student innovation plan of Jiangsu Province.

\section{References}

1. Liu GL, Ge Y, Jiang C, Study on Photogrammetric Measurement of Human Body for Garment Design, The 6th International Conference on Silk, 2007;9:315-316

2. Huang $\mathrm{XL}$, Kuang $\mathrm{CY}$, Liu GL, Prediction of the Main Girths of Human Body Based on Photogrammertric Measurement, The 6th International Conference on Silk. 2007(9).p. 300

3. Zhang SJ, Ding XJ, Zou FY. Research on the Relationship between Data Extracted from 3D Body Scanner and Manual Data[J]. Journal of Zhejiang Sci-Tech University 2006; (23):298-300

4. Lin DJ, Sun XD. Technique of Measurement Extration Based on 3D Human Body Scanning Data[J].Journal of Beijing Institute of Clothing Technology:2005; 25(3):36-41

5. Tian QG, Ge BZ, Du P, Yu DY, Lu QN. Measurement of human figure size based on laser 3D scanning[J]. Optics and Precision Engineering: 2007;15(1):84-87

6. Su JQ, Liu GL. Techniques of Efficient 3D Human Body Modeling and Feature Measurements Extraction Based on Reverse Engineering, The Textile Bioengineering and Informatics Society Proceeding 2009, HongKong, pp. 645-648.

7. Liu GL, Ge Y, Jiang C. Study on Photogrammetric Measurement of Human Body for Garment Design, The 6th International Conference on Silk, 2007(9):315-316

8. Qian Q, Huang XL, Liu GL. Research on Prediction Methods of Limbs Girths of Young Females[j]. Journals of Suzhou University (Engineering Science Edition) 2008; 28(6):24-27

9. Ge Y, Liu GL. Research of camera body measurement for the garment industry. Textile Journal 2007;28(10):78-81

10. Kuang CY, Zhang QC, Kong HY, Liu GL. Measurement and analysis of body characteristics of middle-aged male. Transaction of Soochow University (Engineering Edition) 2008;28:17-22.

11. Qian Q, Huang XL, Liu GL. Prediction Method of Young women's body circumference measurements. Transaction of Soochow University (Engineering Edition) 2008,28:24-28.

12. Kuang CY, Liu GL. Research and applications of non-contact body measurement technology.Foreign silk 2008;6:23-24.

13. Kuang CY, Liu GL. Silhouette Extract from Human Body Image Based on Color Clustering Analysis, The 6thInternational Conference on Silk,2007;9:303. 